\title{
Invaginación intestinal como signo guía de enfermedad celíaca. Un caso clínico pediátrico
}

\author{
Intestinal intussusception as a key sign of Celiac Disease. A pediatric case report
}

\author{
Med. Adj. Beatriz Minguez Rodrígueza, Med. Adj. Sandra Montells Fusterb, Med. Adj. Marta Lomba Estévezc, \\ Med. Adj. Cristina Molera Busoms ${ }^{a}$ Med. Adj. Dr. Javier Martín de Carpi. ${ }^{a}$
}

\section{RESUMEN}

La invaginación intestinal es la causa más frecuente de obstrucción intestinal entre los 6 y los 36 meses de edad. La mayoría son idiopáticas. Se ha descrito la asociación entre la enfermedad celíaca y la invaginación intestinal en la población pediátrica. Se presenta el caso de un varón de 23 meses ingresado por estancamiento ponderal en cuyo estudio ecográfico se observaron invaginaciones íleo-ileales asintomáticas repetidas. Palabras clave: invaginación intestinal, enfermedad celíaca, retraso ponderal.

\begin{abstract}
Intestinal intussusception is the most frequent cause of intestinal obstruction between 6 and 36 months of age, the majority being idiopathic. The association between celiac disease and intestinal intussusception in the pediatric population has been described. We present the case of a 23-month-old male admitted due to a failure to thrive. In his ultrasound study recurrent asymptomatic ileo-ileal invaginations were found. Key words: intestinal intussusception, celiac disease, failure to thrive.
\end{abstract}

http: / / dx.doi.org/10.5546/ aap.2019.e188

Cómo citar: Mínguez Rodríguez B, Montells Fuster S, Lomba Estévez M, Molera Busoms C, Martín de Carpi J. Invaginación intestinal como signo guía de enfermedad celíaca. Un caso clínico pediátrico. Arch Argent Pediatr 2020;118(2):e188-e190.

a. Servicio de Gastroenterología, Hepatología y Nutrición, Hospital Sant Joan de Déu Barcelona, Esplugues de Llobregat.

b. Servicio de Pediatría, Althaia, Xarxa Assistencial Universitària de Manresa, FP, Manresa.

c. Servicio de Pediatría, Complejo Hospitalario Universitario de Pontevedra, Pontevedra. España.

Correspondencia:

Dra. Beatriz Mínguez Rodríguez:

beatriz.minguez.rodriguez@gmail.com

Financiamiento: Ninguno.

Conflicto de intereses: Ninguno que declarar.

Recibido: 11-3-2019

Aceptado: 3-10-2019

\section{INTRODUCCIÓN}

La invaginación intestinal es la causa más frecuente de obstrucción intestinal entre los 6 y los 36 meses de edad. La mayoría son idiopáticas, y se encuentra la causa en el $25 \%$ de los casos. ${ }^{1,2}$ Se ha descrito la asociación entre enfermedad celíaca (EC) e invaginación intestinal en la población pediátrica, previamente conocida en los adultos. ${ }^{3,4}$

Se presenta el caso de un varón con estancamiento ponderal, en cuyo estudio ecográfico se observaron invaginaciones íleoileales repetidas, aunque asintomáticas.

\section{CASO CLÍNICO}

Varón de 23 meses de edad, sin antecedentes familiares ni patológicos de interés, que ingresó por un cuadro de estancamiento ponderal, hiporexia y estreñimiento de dos meses de evolución. Presentaba un descenso del percentil 75-85 de peso hasta el percentil 8 desde el inicio de la clínica. Hábito deposicional previo normal.

En la exploración física, se destacaba un peso de 10,4 kg (-1,43 desvíos estándar-DE-, P8), talla de $81,5 \mathrm{~cm}$ (-1,88 DE, P3), aspecto distrófico, escaso panículo adiposo y abdomen muy globuloso, aunque depresible y sin masas ni megalias. Como estudio inicial, en otro centro, se realizó un análisis de sangre, que incluía perfil nutricional, inflamatorio, hepático, lipídico, renal y estudio de EC (anticuerpos antitransglutaminasa inmunoglobulina A - IgA-, antiendomisio IgA y antigliadina $\operatorname{Ig} \mathrm{A})$, con resultado normal.

A nivel radiológico, se practicó una radiografía simple de abdomen, que mostraba distensión del marco cólico con abundante material fecal, y se amplió el estudio con un enema opaco, que descartó megacolon y estenosis en el colon distal. En la ecografía abdominal, se observó una imagen compatible con invaginación íleo-ileal. Se inició la pauta de desimpactación con polietilenglicol, que resultó efectiva, pero, al persistir el rechazo de la alimentación, la irritabilidad, la astenia y la marcada distensión abdominal, ingresó en nuestro Centro. 
Se decidió repetir la ecografía abdominal para reevaluar la invaginación intestinal y, en esta ocasión, se observaron dos invaginaciones íleo-ileales nítidas pero asintomáticas (Figura 1) y signos de inflamación de la pared de las asas intestinales, lo que fue compatible con un proceso malabsortivo como primera opción. El linfoma como etiología parecía poco probable ante la edad, la ausencia de adenopatías, megalias y alteraciones analíticas compatibles con lisis tumoral o proceso linfoproliferativo.

Dada la exploración clínica tan sugestiva de EC y estos hallazgos ecográficos, se repitieron las serologías y se obtuvieron unos anticuerpos antitransglutaminasa IgA positivos (mayores de $80 \mathrm{U} / \mathrm{ml}$ ) y HLA-DQ2 positivo (DQA ${ }^{*} 0501$, DQB1*0201). En este momento, con el fin de confirmar el diagnóstico de EC, se completó el estudio con endoscopía digestiva alta con toma de biopsias, y se observaron imágenes de la mucosa festoneada y datos histológicos compatibles con atrofia vellositaria en grado Marsh 3. Tras iniciar una dieta sin gluten, el paciente ha presentado buena evolución con resolución de la sintomatología.

\section{COMENTARIO}

La mayoría de las invaginaciones intestinales son idiopáticas. Se han asociado múltiples causas y las más importantes son el divertículo de Meckel, los pólipos intestinales, el linfoma y las vasculitis IgA, entre otras. ${ }^{2}$ Aunque es infrecuente, se ha asociado la EC con esta entidad en pediatría; existen publicaciones y la mayoría son casos clínicos aislados. Se ha descrito una prevalencia de invaginación intestinal en la población pediátrica con $\mathrm{EC}$ del $1,2 \%$ respecto a un $0,07 \%$ en la población pediátrica sana. ${ }^{4} \mathrm{Sin}$ embargo, en un estudio prospectivo reciente, se ha observado una frecuencia del $25 \%$ en los pacientes con diagnóstico reciente previo al inicio de la dieta exenta de gluten. ${ }^{5}$

Su patogenia es incierta; pueden intervenir cambios estructurales del epitelio, inflamación del intestino delgado con mayor rigidez de la pared y aumento de su diámetro, así como la dismotilidad intestinal., ${ }^{2,5}$ Se han relacionado la hipoalbuminemia, la distensión abdominal y el grado de afectación histopatológica duodenal como factores favorecedores. ${ }^{5}$ En la mayoría de los casos, se trata de invaginaciones intestinales que afectan al intestino delgado, asintomáticas y autolimitadas, que se resuelven tras el inicio de la dieta sin gluten, sin recurrencia posterior. ${ }^{4,5}$ No hay suficiente evidencia sobre la necesidad de investigar la EC tras presentar un cuadro de invaginación intestinal sin filiar; ${ }^{3}$ sin embargo, sí debe ser un diagnóstico para tener en cuenta, sobre todo, en el caso de asociar otra clínica compatible con un cuadro de malabsorción. ${ }^{4}$

En nuestro paciente, la sospecha de EC fue elevada, pero el primer estudio resultó negativo. Esta discordancia puede deberse a la diferente sensibilidad entre las técnicas usadas

FIGURA 1. Se observan dos imágenes en pseudorriñón o diana localizadas en el intestino delgado compatibles con invaginaciones intestinales ileo-ileales

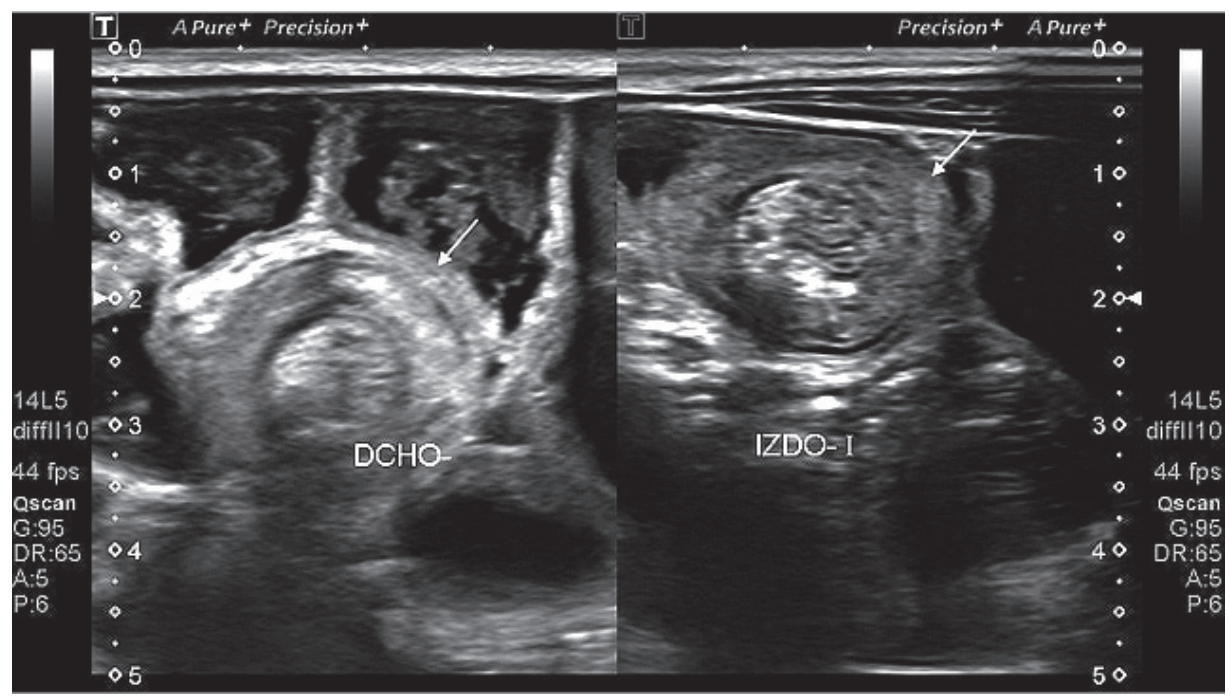


en los dos centros o, más probablemente, a la edad del paciente, ya que se ha descrito una inmunodeficiencia transitoria en los menores de 2 años. ${ }^{6}$ El hallazgo de las invaginaciones intestinales íleo-ileales sin otras alteraciones anatómicas ni analíticas condujo a la repetición del estudio, lo que confirmó el diagnóstico. Como en los casos descritos previamente en la literatura, tras la retirada del gluten de la dieta, se resolvió el cuadro clínico; no volvió a presentar episodios de invaginación intestinal y mantuvo una adecuada ganancia ponderal. ${ }^{7-10}$

\section{REFERENCIAS}

1. Ntoulia A, Tharakan SJ, Reid JR, Mahboubi S. Failed Intussusception Reduction in Children: Correlation Between Radiologic, Surgical, and Pathologic Findings. AJR An J Roentgenol. 2016; 207(2):424-33.

2. Vo NJ, Sato TT. Intussusception in children. UpToDate. [Acceso: 23 de diciembre de 2018]. Disponible en: https: / / www.uptodate.com/ contents / intussusception-inchildren.
3. Ludvigsson JF, Nordenskjöld A, Murray JA, Olén O. A large nationwide population-based case-control study of the association between intussusception and later celiac disease. BMC Gastroenterol. 2013; 13:89.

4. Reilly NR, Aguilar KM, Green PH. Should intussusception in children prompt screening for celiac disease? J Pediatr Gastroenterol Nutr. 2013; 56(1):56-9.

5. Borkar VV, Poddar U, Thakral A, Agarwal J, et al. Intussusception in celiac disease: Is it a common feature in children? J Gastroenterol Hepatol. 2018; 33(2):380-4.

6. Grupo de trabajo del Protocolo para el diagnóstico precoz de la enfermedad celíaca. Protocolo para el diagnóstico precoz de la enfermedad celíaca. Canarias: Ministerio de Sanidad, Servicios Sociales e Igualdad. Servicio de Evaluación del Servicio Canario de la Salud (SESCS); 2018.

7. Goyal M, Ellison AM, Schapiro E. An unusual case of intussusception. Pediatr Emer Care. 2010; 26(3):212-4.

8. Gheibi S. Association between Celiac Disease and Intussusceptions in Children: Two Case Reports and Literature Review. Pediatr Gastroenterol Hepatol Nutr. 2013; 16(4):269-72.

9. Fernandes VP, Lomazi EA, Bellomo-Brandao MA. A rare association of intussusception and celiac disease in a child. Sao Paulo Med J. 2016; 134(5):457-60.

10. Mushtaq N, Marven S, Walker J, Puntis JW, et al. Small Bowel Intussusception in Celiac Disease. J Pediatr Surg. 1999; 34(12):1833-5. 